\title{
O direito na sociedade da informação: a proteção aos direitos autorais e direitos conexos frente às novas tecnologias*
}

\author{
The right in the information society: the \\ protection of copyright and related rights to \\ new technologies
}

Marcelo Tadeu Nascimento ${ }^{1}$ Caio Sperandeo de Macedo ${ }^{2}$
Recebido em: 01/09/2016. Aprovado em: 14/09/2016.

1 Mestrando em Direito da Sociedade da Informação do Centro Universitário das Faculdades Metropolitanas Unidas em São Paulo (FMU-SP), pós-graduado Lato Sensu em Processo (UNAERP-2013) e Bacharel em Ciências Jurídicas e Sociais (FIRP-1997). Advogado.

2 Professor permanente da Pós-Graduação do Programa de Mestrado em Direito da Sociedade da Informação e do curso de Graduação em Direito, ambos do Centro Universitário das Faculdades Metropolitanas Unidas - FMU/SP, São Paulo. Membro Efetivo da Comissão Permanente de Meio Ambiente da OABSP, no Grupo de Trabalho de Meio Ambiente Digital. Advogado militante com atuação na área de direito da sociedade da informação, direito educacional, educação superior brasileira, políticas públicas. Possui Doutorado em Filosofia do Direito pela Pontifícia Universidade Católica de São Paulo, PUC/SP (2014), Brasil, Mestrado em Direito do Estado pela Pontifícia Universidade Católica de São Paulo (2005) e Graduação em Direito pela Pontifícia Universidade Católica de São Paulo (1996).

\section{Resumo}

O presente artigo trata do direito na sociedade da informação e suas características para fins de proteção às violações dos direitos autorais e conexos, isto é, da ciência jurídica na sociedade do conhecimento e da tecnologia enquanto orientadora na aplicação da legislação e proteção dos direitos autorais e conexos violados por meio do uso indevido das novas tecnologias (internet e aplicativos). O método de pesquisa será a revisão bibliográfica e a consulta legislativa, acrescendo dados estatísticos acerca das novas mídias. Na conclusão, será verificado que, embora a legislação não acompanhe as modificações sociais, cada vez mais velozes e irrestritas, é possível, por meio dos princípios constitucionais norteadores, alcançar proteção aos direitos autorais e conexos violados.

Palavras-chave: Direito na sociedade da informação. Direitos autorais e conexos. Novas tecnologias. Proteção.

\begin{abstract}
This article deals with the rights in the information society and its characteristics for protection infringements of copyright and related rights, that is, of legal science in the knowledge society and technology as guiding the enforcement and protection of copyright and related violated through misuse of new technologies (internet and applications). The research method is a literature review, legislative and jurisprudential consultation, adding statistics about new media. In conclusion, it will be found that although the legislation does not follow social changes, increasingly fast and unrestricted, it is possible by means of the guiding constitutional principles to achieve protection of copyright and related rights violated. Keywords: Law in the information society. Copyright and related rights. New technologies. Protection.
\end{abstract}




\section{Introdução}

O objetivo do presente trabalho não é trazer proposições em perspectiva ou pontuar sobre a necessidade de novas leis para fins de proteção aos direitos autorais e conexos, mas sim anotar que o arcabouço legislativo nacional, ainda que careça ser melhor ajustado para alguns (o que não será discutido), permite a proteção de tais direitos. Outrossim, não se adentrará nos pormenores de cada obra (musical, audiovisual etc.), utilizando-se, genericamente, direitos autorais e conexos.

$\mathrm{O}$ direito ou a ciência jurídica na sociedade da informação, ante a alta complexidade imprimida aos problemas jurídicos, exige que se aborde e enquadre qualquer tema sob o ponto de vista antropológico, econômico, sociológico, político, filosófico, ético, histórico etc. E, além disso, torna-se imprescindível a aplicação do princípio da alteridade, que implica colocar no lugar do outro. A problemática envolvendo, de um lado, o direito dos autores, e de outro, o direito ao acesso à cultura, detém esse grau de complexidade, exigindo que se aplique a norma sob o enfoque zetético, sem se descurar do enfoque dogmático.

Socialmente, nos últimos vinte anos (aproximadamente), as estruturas que tinham a atribuição de manter a exclusividade sobre as manifestações artísticas e do conhecimento sofreram uma inovação radical em si mesmas. Com o surgimento de novas tecnologias digitais, cujas caraterísticas são convergentes e carregadamente excessivas em termos de fluxo - todas disponíveis na rede mundial de computadores -, houve a abrangência entre emissores e receptores. Cuida-se de uma realidade em que o artista, o intérprete ou o autor não estão mais confinado nos ambientes voltados à arte (galerias, teatros, apresentações musicais, cinemas, exposições etc.), podendo o indivíduo publicar suas criações ou ideias, sejam originais ou oriundas de obras primígenas, mediante um 'click'. Não é só. É uma realidade em que os bens simbólicos são compartilhados, divulgados, expostos e modificados por meio de novas tecnologias, principalmente a internet (por meio de programas e aplicativos), assim, desponta como preocupação acadêmica, legislativa e do público em geral a questão da proteção aos direitos autorais e conexos no atual cenário.

O método aqui empregado é o da análise da literatura, legislação e dados estatísticos do funcionamento da internet enquanto meio de informação e espaço de exposição pública. $\mathrm{O}$ conjunto dessas atividades analíti- cas empregadas é que permitiu a verificação da hipótese formulada.

O estudo se justifica do ponto de vista social na medida em que as novas tecnologias se mostraram como um meio de criação e transmissão, exponenciais, hábeis às violações dos direitos do autor e conexos. Do ponto de vista acadêmico, se justifica, igualmente, na medida em que adensa a produção do conhecimento sobre atividades protetivas, levando-se em conta os postulados jurídicos já firmados.

Apresentadas essas considerações sobre o tema, delimitação, objetivo, hipótese, metodologia e justificativas, cabe situar o campo de incidência do estudo e o ambiente no qual ocorre, que é a rede mundial de computadores e suas plataformas, as quais se consolidaram no Brasil a partir de 1995 e a subsequente organização do desenvolvimento do presente estudo.

Assim, no item 2, aborda-se a complexidade da sociedade da informação e seus reflexos na apreensão e aplicação do direito. Em seguida, no item 3, estudam-se as novas tecnologias na sociedade da informação. Adiante, nos itens 4 e 5 , respectivamente, adentra no estudo dos aspectos gerais e das violações dos direitos autorais e conexos. E, no item 6, antes das considerações finais, aborda-se a proteção jurídica aos direitos autorais e conexos na atual sociedade da informação, concluindo com a ideia de que é possível uma proteção no cenário atual.

\section{0 direito na sociedade da informação}

Entende-se a sociedade da informação (pós-moderna ou pós-industrial) "[...] como a contemporaneidade onde a informação, bem intangível, constitui-se no maior valor e é produto de esforço intelectual que não depende de qualquer base material. Nesse cenário, o poder é difuso e disperso"3

Eduardo Iamundo, ao tratar do tema, define a sociedade da informação como aquela capitalista afluente em que sua predominância está, estritamente, ligada ao capital financeiro, à prestação de serviços e ao conhecimento científico ou tecnológico ${ }^{4}$. E afirma:

3 BARBOSA, Marco Antonio. Pluralismo jurídico na sociedade da informação. Direitos Fundamentais \& Justiça, Porto Alegre, ano 6, n. 20, p. 114-134, jul./set. 2012. p. 130-131.

4 IAMUNDO, Eduardo. Sociologia e antropologia do direito. São Paulo: Saraiva, 2013. p. 132. 
O conhecimento e a informação adquirem na sociedade afluente profundo significado e tornam-se mercadorias muito valorizadas. É oportuno esclarecer que o conhecimento da esfera científica tem maior ou menor valor, conforme a tecnologia que pode ser produzida e vendida. Em outras palavras, quanto maior a possibilidade que um conhecimento científico tem de transformar-se em mercadoria consumível, maior será seu valor. Quanto mais preciosa a informação no sentido de fonte geradora de benefícios, maior o seu valor no mercado. ${ }^{5}$

É imprescindível, ainda, comentar o fenômeno da globalização, cuja relevância ocorre a partir de 1980 com as intensas modificações políticas e econômicas de então, com destaque na seara política para o desmembramento da União da República Socialista Soviética, a queda do muro de Berlim e a hegemonia dos Estados Unidos da América e a visão internacionalista da política das relações entre os Estados-nação. Com as novas tecnologias da informação (intensas e aperfeiçoadas), as diretrizes para os procedimentos administrativos e financeiros são realizadas por programas de computadores, intensificando a sofisticação do processo burocrático (controle) na sociedade contemporânea. Outro aspecto da globalização é a cultura, isto é, a migração de usos e de costumes e a imposição de certas práticas culturais ${ }^{6}$. Leia-se, "No mundo globalizado, o acesso à informação tem se tornado essencial para que os usuários possam exercer cidadania"”.

Frente a essas transformações, o direito precisa ser compreendido em sua função social ou como um "conhecimento" ou "saber" que, também, serve à luta ou à tensão social emanada e frequente no mundo vivenciado (de alta complexidade). Ademais, o direito é entendido como meio de mudança ou prática virtuosa em prol do homem. Desse modo, com as novas tecnologias, o direito, na sociedade da informação, deve levar em conta a legitimidade dos atores envolvidos. Conforme alerta Tércio Sampaio Ferraz Junior,

[...] As sociedades estão em transformação e a complexidade do mundo está exigindo novas formas de manifestações do fenômeno jurídi-

IAMUNDO, Eduardo. Sociologia e antropologia do direito. São Paulo: Saraiva, 2013. p. 132.

6 IAMUNDO, Eduardo. Sociologia e antropologia do direito. São Paulo: Saraiva, 2013. p. 132-133.

7 SOUSA, Rosilene Paiva Marinho de et al. O exercício da arquitetura da informação na web: reflexões relativas à lei dos direitos autorais. Revista eletrônica de biblioteconomia e ciência da informação, Santa Catarina, v. 18, n. 36, p. 107128, jan./abr. 2013. p. 124. co. É possível que, não tão distantemente no futuro, essa forma compacta do direito instrumentalizado, uniformizado e generalizado sob a forma estatal de organização venha a implodir, recuperando-se, em manifestações espontâneas e localizadas, um direito de muitas faces, peculiar aos grupos e às pessoas que os compõem. [...] Por isso tudo, a consciência da nossa circunstância não deve ser entendida como um momento final, mas como um ponto de partida. Afinal, a ciência não nos libera porque nos torna mais sábios, mas é porque nos tornamos mais sábios que a ciência nos libera.[...] pensar o direito, refletir sobre suas formas hodiernas de atuação, encontrar-lhe um sentido, para então vivê-lo com prudência, esta marca virtuosa do jurista $[\ldots]{ }^{8}$

As transformações sociais e a divulgação do avanço das ciências misturam certezas e incertezas com um resultado paradoxal: individualização e o questionamento da complexidade social. Isto torna difícil a pacificação social pelo direito visto sob o enfoque do dogma (somente), desacreditando os procedimentos jurídicos como factíveis para realizar o direito. Leia-se, propicia uma crise de legitimidade das instituições. A sociedade da informação:

[...] realiza muito menos do que se propõe e frequentemente transmite informação ambivalente, manipulada e manipulável assim como, a globalização engloba muito menos pessoas e povos do que o discurso ufanista sobre ela pretende. A mercadoria vem antes, e neste mercado, a informação e o conhecimento também são produtos ${ }^{9}$.

Marco Antonio Barbosa, citando José Eduardo Faria, avançando na observação do direito focado no dogma, pontua:

[...] os novos paradigmas exigem a busca de um Direito enquanto conjunto de regras em movimento e continuamente reformuladas, inclusive por forças extra-legislativas e extra-estatais. Desse modo o próprio objeto da Ciência Jurídica é deslocado, não se encontrando mais no conjunto de normas instituído em dogmas, mas, exatamente, nos próprios fatos sociais $[. . .]^{10}$.

O direito, em relação à resolução de conflitos na sociedade da informação (e em um mundo globalizado),

FERRAZ JUNIOR, Tércio Sampaio. Introdução ao estudo do direito: técnica, decisão, dominação. 8. ed. São Paulo: Atlas, 2015. p. 7-9.

9 BARBOSA, Marco Antonio; SANTOS, Marco Aurelio Moura dos. O direito na sociedade da informação e perspectivas para a sociedade do conhecimento. Direitos Fundamentais \& Justiça, Porto Alegre, ano 8, n. 28, p. 82-99, jul./set. 2014. p. 88.

10 BARBOSA, Marco Antonio. Pluralismo jurídico na sociedade da informação. Direitos Fundamentais \& Justiça, Porto Alegre, ano 6, n. 20, p. 114-134, jul./set. 2012. p. 132. 
não pode ser enfatizado e restringido ao dogma, mas, com base neste, avançando para a zetética ${ }^{11}$, portanto, o direito na sociedade da informação liga-se, essencialmente, à ética, à responsabilidade ${ }^{12}$, ao contexto e ao princípio da alteridade.

\section{As novas tecnologias na sociedade da infor- mação}

Os principais instrumentos que permitiram a convergência de dados e a respectiva divulgação são a internet (enquanto instrumento) e, respectivamente, as redes sociais (como forma), na construção, violação e divulgação de obras culturais ${ }^{13}$.

Em idos de 1960, a internet ou rede mundial teve seu surgimento. O idealizador foi o exército Americano com a proposta de criar um modo de transmitir dados entre dois aparelhos de computador. Já ao final dos anos 60, a Agência de Projetos Avançados (ARPA), do Departamento de Defesa Americano, transferiu para a Rand Corporation a tarefa de desenvolver um sistema de telecomunicações que protegesse a comunicação dos comandantes do país, no caso de ataque nuclear. Esse projeto ganhou o nome de Projeto Arpanet ${ }^{14}$.

Com relação ao Projeto Arpanet, importante salientar que pequenas redes locais (LAN) foram criadas e posicionadas em lugares estratégicos do país, e ligadas por meio de redes de telecomunicação geográfica

11 "O enfoque dogmático [...] considera que a solução já está previamente dada ou pressuposta no sistema de normas (dogmas) [...] o enfoque zetético revela-se como um saber especulativo, sem compromissos imediatos com a ação, que envolve questionamentos extraídos de diversas áreas do conhecimento." ASSIS, Olney Queiroz; KUMPEL, Vitor Frederico. Manual de antropologia jurídica. São Paulo: Saraiva, 2015. p. 268-269.

12 BARBOSA, Marco Antonio. Pluralismo jurídico na sociedade da informação. Direitos Fundamentais \& Justiça, Porto Alegre, ano 6, n. 20, p. 114-134, jul./set. 2012. p. 132.

13 "O Direito Autoral, no Brasil, é regulado pela Lei 9.610/98, também chamada de LDA. Nas últimas décadas, com a evolução vertiginosa do contexto tecnológico, a referida lei tornou-se, em parte, obsoleta e revelou-se objeto de críticas em relação a sua atuação, que se configura incompatível com as necessidades da sociedade informacional onde impera a Internet." BRAUN, Michele; ADOLFO, Luiz Gonzaga Silva. A gestão coletiva dos direitos autorais no Brasil: uma reflexão sobre o contexto tecnológico contemporâneo e a Lei 9610/98. Direito, Estado e Sociedade, Rio de Janeiro, n. 42, p. 194-212, jan./jun. 2013. p. 194.

14 PAESANI, Liliana Minardi. Direito e internet: liberdade de informação, privacidade e responsabilidade civil. 6. ed. São Paulo: Atlas, 2013. p. 10.
(WAN). Assim, se algum ponto estratégico fosse destruído, as "redes conexas" compostas por redes locais longe umas das outras, todavia ligadas entre si, protegeriam a comunicação (por meio das redes coligadas). Esse modelo sistemático (de redes interligadas) foi nominado de Internet (Inter Networking) ${ }^{15}$.

Muito embora a internet tenha ganhado ramificações em 1973, quando o Departamento de Pesquisa Avançada da Universidade da Califórnia e responsável pelo Projeto Arpanet registrou o Protocolo de Controle da Transmissão (protocolo TCP/IP - Internet Protocol ou Protocolo Internet) ${ }^{16}$, somente a partir do final da década de 80 e início da década de 90, o acesso aos microcomputadores, em face da redução de custos na produção, ultrapassou a marca de um milhão de usuários. Também, nessa década, houve o direcionamento da internet para fins culturais e comerciais. A internet tornou-se uma realidade para boa parte da humanidade e seus efeitos podem ser observados na alteração do cotidiano de grande número de pessoas. Sem adentrar na febre dos smartphones, responsáveis pela inserção digital de milhares de pessoas, estimam-se 93 milhões de usuários ${ }^{17}$.

Para se ter uma clara ideia, a Pesquisa Nacional por amostra de Domicílios (PNDA) de $2013^{18}$ constatou que $49,4 \%$ da população brasileira, ou seja, 85,6 milhões, tem acesso à internet em seus domicílios, levando em conta o acesso de pessoas acima dos 10 anos de idade que utilizaram a rede, pelo menos uma vez, nos últimos 90 dias da entrevista. Outro dado refere-se ao fato de que $97,7 \%$ estão conectados por banda larga, com alto fluxo de dados.

15 PAESANI, Liliana Minardi. Direito e internet: liberdade de informação, privacidade e responsabilidade civil. 6. ed. São Paulo: Atlas, 2013. p. 10.

16 PAESANI, Liliana Minardi. Direito e internet: liberdade de informação, privacidade e responsabilidade civil. 6. ed. São Paulo: Atlas, 2013. p. 10.

17 GOMES, Helton Simões: "Os números mostram que a população conectada cresceu, enquanto a de indivíduos 'móveis' avançou em ritmo mais acelerado. Se em 2010, os internautas eram 82 milhões, em 2015, passaram a 117 milhões. Já o número de donos de smartphone pulou de 10 milhões para 93 milhões no mesmo período". GOMES, Helton Simões. Conexão à internet via smartphone dobra no Brasil diz Google. Disponível em: <http://g1.globo.com/ tecnologia/noticia/2015/08/conexao-internet-smartphone-dobra-no-brasil-em-2015-diz-google.html>. Acesso em: 15 jun. 2016.

18 C.f. ACESSO à internet chega a 49,4\% da população brasileira. Brasília: EBC, 2015. Disponível em: <http://www. ebc.com.br/tecnologia/2015/04/acesso-internet-chega-494-da-populacao-brasileira>. Acesso em: 02 nov. 2015. 
Segundo Manuel Castells, vivemos em uma sociedade em rede, localizada na "Galáxia da Internet". ${ }^{19}$ Segundo o mesmo Autor,

A influência das redes baseadas na Internet vai além do número de seus usuários: diz respeito também à qualidade do uso. Atividades econômicas, sociais, políticas, e culturais essenciais por todo o planeta estão sendo estruturadas pela Internet e em torno dela, como por outras redes de computadores [...]. ${ }^{20}$

Dentro dessa realidade, é evidente que a sociedade informacional compartilha tudo o que sabe, o que vê, o que ouve e o que sente, muito diferente de outras épocas, quando todo o conhecimento era, de certa forma, centralizado. Essas facilidades e possibilidades transformaram o mundo, consolidando o 'virtual' e a 'cultura digital' ${ }^{21}$. Atualmente, ao se falar em direitos autorais e conexos, incluem-se, além das obras clássicas (artísticas e literárias), as obras audiovisuais, os programas de computador e as transmissões.

Nesse cenário, salta aos olhos que as novas tecnologias e sua exacerbação na interação social causaram profundo impacto na criação e utilização das obras protegidas no universo da internet, causando instabilidade e insegurança $\mathrm{a}^{22}$.

\section{Aspectos gerais dos direitos autorais e cone- xos}

Os direitos autorais e conexos ou direitos sobre a propriedade intelectual (de maneira geral) repousam na prerrogativa garantida de poder autorizar ou impedir,

19 "A Internet é um meio de comunicação que permite, pela primeira vez, a comunicação de muitos com muitos, num momento escolhido, em escala global. Assim como a difusão da máquina impressora no Ocidente criou o que MacLuhan chamou de a 'Galaxia de Gutenberg', ingressamos agora num novo mundo de comunicação: a Galáxia da Internet [...]". CASTELLS, Manuel. A galáxia da internet: reflexões sobre a internet, os negócios e a sociedade. Rio de Janeiro: J. Zahar, 2003. p. 8.

20 CASTELLS, Manuel. A galáxia da internet: reflexões sobre a internet, os negócios e a sociedade. Rio de Janeiro: J. Zahar, 2003. p. 8.

21 BRAUN, Michele; ADOLFO, Luiz Gonzaga Silva. A gestão coletiva dos direitos autorais no Brasil: uma reflexão sobre o contexto tecnológico contemporâneo e a Lei 9610/98. Direito, Estado e Sociedade, Rio de Janeiro, n. 42, p. 194-212, jan./jun. 2013. p. 197.

22 NINNI, Karina. O direito autoral na era da informação. Disponível em: <http://bibliotecadigital.fgv.br/ojs/index. php/pagina22/article/viewFile/28718/27577>. Acesso em: 30 jun. 2016. isto é, um poder de interditar, lembrando que, também, envolvem as exceções e limitações que a lei impõe em face do direito à educação e à informação, devendo ser visto sob sua perspectiva histórica, democrática e humanista ${ }^{23}$. Ademais, a Constituição Federal de 1988, no seu Título VIII (Da Ordem Social), Capítulo III, Seção II, por meio do artigo $215^{24}$, incumbiu ao Estado a promoção da garantia do exercício, acesso e difusão das manifestações culturais, destacando, nesse particular, a função social de tais direitos.

A espécie humana, historicamente, desenvolveu técnicas para criar, aprimorar e manipular os elementos da natureza, visando seu próprio benefício. Em relação aos trabalhos com a argila ou o barro, madeira, pedras, minerais até a última geração de computadores, o que se tem é a subjugação da natureza pela capacidade criativa do homem, sendo esta digna de proteção. Parafraseando o Professor Doutor Newton Silveira, é possível assentar:

Fundamentalmente, o trabalho criativo é de um só tipo, seja no campo das ideias abstratas, das invenções ou das obras artísticas. O que se protege é o fruto dessa atividade, quando ela resulta em uma obra intelectual, ou seja, uma forma com unidade suficiente para ser reconhecida coo ela mesma. O fundamento do direito sobre tais obras se explica pela própria origem da obra: o indivíduo. A obra lhe pertence originalmente pelo próprio processo de criação; só a ele compete decidir revelá-la pondo-a no mundo, e essa decisão não destrói a ligação original entre obra e autor ${ }^{25}$.

23 FRAGOSO, João Henrique da Rocha. Direito autoral: da antiguidade à internet. São Paulo: Quartier Latin do Brasil, 2009. p. 382.

24 Art. 215. O Estado garantirá a todos o pleno exercício dos direitos culturais e acesso às fontes da cultura nacional, $\mathrm{e}$ apoiará e incentivará a valorização e a difusão das manifestações culturais. $\$ 1^{\circ} \mathrm{O}$ Estado protegerá as manifestações das culturas populares, indígenas e afro-brasileiras, e das de outros grupos participantes do processo civilizatório nacional. $\$ 2^{\circ}$ A lei disporá sobre a fixação de datas comemorativas de alta significação para os diferentes segmentos étnicos nacionais. $\$ 3^{\circ} \mathrm{A}$ lei estabelecerá o Plano Nacional de Cultura, de duração plurianual, visando ao desenvolvimento cultural do País e à integração das ações do poder público que conduzem à: I defesa e valorização do patrimônio cultural brasileiro; II produção, promoção e difusão de bens culturais; III formação de pessoal qualificado para a gestão da cultura em suas múltiplas dimensões; IV democratização do acesso aos bens de cultura; $\mathrm{V}$ valorização da diversidade étnica e regional. BRASIL. Constituição (1988). Constituição da República Federativa do Brasil. Disponível em: <http://www.planalto.gov.br/ccivil_03/constituicao/ constituicaocompilado.htm>. Acesso em: 30 jun. 2016.

25 SILVEIRA, Newton. Propriedade intelectual. 5. ed. São Paulo: Manole, 2014. p. 12. 
A partir do Decreto de 19 de julho de 1793 (apresentado por Joseph Lakanal), na França, consagrou-se o direito exclusivo e discricionário dos autores sobre suas obras e a repressão à contrafação, estendendo a proteção aos escritores, compositores musicais, pintores, desenhistas, bem como obras de todos os gêneros, anotando-se que, no campo moral, já em 1666, herdeiros de Pascal, o pensador francês, se opuseram a editores que visavam reconstituir lacunas em suas obras ${ }^{26}$.

A proteção aos direitos intelectuais se desenvolveram em duas vertentes. Internacionalmente, por meio de tratados e convenções (Convenção de Paris/1883; Convenção de Berna/1886; União de Berna e Paris/1893 [BIRPI - Escritório Internacional para Propriedade Intelectual]; Convenção de Roma/1961; Conferência de Estocolmo/1967 [OMPI - Organização Mundial da Propriedade Intelectual]).

Já na seara nacional, a proteção ganhou corpo por meio da Constituição Federal (CF/67 e CF/88 [excluído da $\mathrm{CF} / 37$ e $\mathrm{CF} / 46])$, a qual alçou e manteve tais direitos como fundamentais, vindo a legislação infraconstitucional a especificar a proteção e a limitação a tais direitos (Lei Federal no 9610/1998 [alterada pela Lei Federal no 12.853/2013]; Lei Federal no 9.609/1998 [software]; Lei Federal no 9.279/1996 [propriedade industrial]; e Lei Federal $n^{\circ} 9.456 / 1997$ [cultivares] etc.).

Traçados esses aspectos gerais de conceito e proteção normativa quanto aos direitos intelectuais, e mais especificamente com relação aos direitos do autor, vislumbra-se, também, os direitos conexos, que pertencem a terceiros, que, com sua atividade, intervêm na própria obra primígena, em suma, relaciona-se ao direito de o artista, intérprete ou executante possuir a proteção quanto às suas próprias criações do espírito, desde que originais e únicas.

Em outras palavras, a reformulação ou reinvenção do intérprete e do executante, titulares de direito novo e exclusivo, pode até ser invocada contra o autor da obra original e lhe garante a contraprestação ao desempenho. Esta é a posição adotada pela doutrina brasileira ${ }^{27}$.

Embora somente com a Convenção de Roma, em 26 de outubro de $1961\left(\right.$ art. $\left.1^{\circ}\right)$, que disciplinou a maté-

\footnotetext{
26 FRAGOSO, João Henrique da Rocha. Direito autoral: da antiguidade à internet. São Paulo: Quartier Latin do Brasil, 2009. p. 53-54.

27 BITTAR, Carlos Alberto. Direito de autor. 6. ed. Rio de Janeiro: Forense, 2015. p. 167.
}

ria no cenário internacional, antes disso, a doutrina local já aventava elementos sobre os direitos conexos ou vizinhos aos direitos do autor ${ }^{28}$, vindo a integrar a legislação interna pelo Decreto n 57.125 de 19 de outubro de 1965, após a aprovação do Congresso Nacional (Decreto Legislativo nº 26 de 1964).

Atualmente, os direitos conexos são tratados no Título V, da Lei Federal no 9610/1998, alterada pela Lei Federal $n^{\circ}$ $12.853 / 13$, podendo-se extrair da junção dos artigos $1^{\text {o29 }}, 7^{030}$,

28 COSTA NETTO, José Carlos. Estudos e pareceres de direito autoral. Rio de Janeiro: Forense, 2015. p. 99: "Hermano Duval, a exemplo de Antonio Chaves, há mais de quarenta anos, portanto anteriormente à primeira convenção internacional que trataria do tema (em Roma, no ano de 1961), já fornecia elementos sobre os direitos conexos ou vizinhos aos direitos de autor. Explicou tratar-se de uma categoria que, se de um lado, decorreu da natural evolução da doutrina - notadamente da doutrina germânica -, de outro lado teve a sua aceitação aumentada pela valorização das invenções modernas, que incontestavelmente vieram dar às obras artísticas, literárias, científicas e musicais uma repercussão até então desconhecida". HERMANO, Duval. Direitos autorais nas invenções modernas. Rio de Janeiro: Andes, 1956. p. 271.

29 Art. $1^{\circ}$ Esta Lei regula os direitos autorais, entendendo-se sob esta denominação os direitos de autor e os que lhes são conexos. BRASIL. Lei Federal n. 9610/1998. Altera, atualiza e consolida a legislação sobre os direitos autorais e dá outras providências. Brasília. 2016. Disponível em: <http://www.planalto. gov.br/ccivil_03/leis/L9610.htm>. Acesso em: 03 jul. 2016.

$30 \quad$ Art. 70 São obras intelectuais protegidas as criações do espírito, expressas por qualquer meio ou fixadas em qualquer suporte, tangível ou intangível, conhecido ou que se invente no futuro, tais como: I - os textos de obras literárias, artísticas ou científicas; II - as conferências, alocuções, sermões e outras obras da mesma natureza; III - as obras dramáticas e dramático-musicais; IV - as obras coreográficas e pantomímicas, cuja execução cênica se fixe por escrito ou por outra qualquer forma; V - as composições musicais, tenham ou não letra; VI - as obras audiovisuais, sonorizadas ou não, inclusive as cinematográficas; VII - as obras fotográficas e as produzidas por qualquer processo análogo ao da fotografia; VIII - as obras de desenho, pintura, gravura, escultura, litografia e arte cinética; IX - as ilustrações, cartas geográficas e outras obras da mesma natureza; $\mathrm{X}$ - os projetos, esboços e obras plásticas concernentes à geografia, engenharia, topografia, arquitetura, paisagismo, cenografia e ciência; XI - as adaptações, traduções e outras transformações de obras originais, apresentadas como criação intelectual nova; XII - os programas de computador; XIII - as coletâneas ou compilações, antologias, enciclopédias, dicionários, bases de dados e outras obras, que, por sua seleção, organização ou disposição de seu conteúdo, constituam uma criação intelectual. $\$ 1^{\circ}$ Os programas de computador são objeto de legislação específica, observadas as disposições desta Lei que lhes sejam aplicáveis. $\$ 2^{\circ}$ A proteção concedida no inciso XIII não abarca os dados ou materiais em si mesmos e se entende sem prejuízo de quaisquer direitos autorais que subsistam a respeito dos dados ou materiais contidos nas obras. $\$$ $3^{\circ}$ No domínio das ciências, a proteção recairá sobre a forma literária ou artística, não abrangendo o seu conteúdo científico ou técnico, sem prejuízo dos direitos que protegem os demais campos da propriedade imaterial. 
$28^{\circ 31}$ e $89^{\circ 32}$ da referida Norma, sua conceituação, abrangência e proteção, calhando anotar a seguinte lição:

[...] a lei dispõe sobre os direitos conexos com a mesma ênfase dada aos direitos do autor. Afinal, a qualidade daquilo que é conexo é a de estar conectada à dimensão do direito de autor, e esta conexão às vezes é a própria forma de concretização e realização do direito de autor. $\mathrm{O}$ que orbita em torno do direito de autor é tão significativo a ele, que recebe o mesmo tratamento e a mesma equivalência legal ao direito de autor"33

Portanto, é sob essa perspectiva que os direitos conexos, conferidos a artistas, intérpretes ou executantes, produtores fonográficos e empresas de radiodifusão são tratados no Brasil, ou seja, recebem proteção integral com a mesma envergadura de direitos do autor dentro das suas similaridades, pontuando-se que, enquanto o direito do autor protege a obra do próprio autor, os conexos defendem determinada categoria de pessoas ou empresas que desempenham um papel importante na interpretação, execução, comunicação ou divulgação de obras junto ao público em geral, cabendo salientar que, muitas vezes, é essa expressão que valoriza ou acresce importância à própria obra do autor.

\section{As violações dos direitos autorais e conexos nas novas tecnologias}

Antes do advento da internet, a televisão figurava como o principal meio de comunicação, uma vez que absorvia diferentes linguagens, constituindo formas múltiplas de disseminação de conteúdos. Atualmente, a rede mundial de computadores, cujo principal atrativo é a junção de textos, imagens e sons digitalizados realiza

$31 \quad$ Art. 28. Cabe ao autor o direito exclusivo de utilizar, fruir e dispor da obra literária, artística ou científica. BRASIL. Lei Federal n. 9610/1998. Altera, atualiza e consolida a legislação sobre os direitos autorais e dá outras providências. Brasília. 2016. Disponível em: <http://www.planalto.gov. br/ccivil 03/leis/L9610.htm>. Acesso em: 03 jul. 2016.

32 Art. 89. As normas relativas aos direitos de autor aplicam-se, no que couber, aos direitos dos artistas intérpretes ou executantes, dos produtores fonográficos e das empresas de radiodifusão. Parágrafo único. A proteção desta Lei aos direitos previstos neste artigo deixa intactas e não afeta as garantias asseguradas aos autores das obras literárias, artísticas ou científicas. BRASIL. Lei Federal n. 9610/1998. Altera, atualiza e consolida a legislação sobre os direitos autorais e dá outras providências. Brasília. 2016. Disponível em: <http://www.planalto.gov.br/ccivil_03/leis/ L9610.htm>. Acesso em: 03 jul. 2016.

33 BITTAR, Carlos Alberto. Direito de autor. 6. ed. Rio de Janeiro: Forense, 2015. p. 167. esse papel, com um detalhe: surge um agente multimídia, o internauta, o qual lê, ouve, assiste, critica, distribui, cria e combina materiais diversos, transitando entre cultura, entretenimento, informação e serviço ${ }^{34}$.

Torna-se prática presente e comum nesse novo canal a colaboração e a divulgação de conteúdos. Isso faz crescer, exponencialmente, a atividade cultural, porquanto uma boa parcela da humanidade deixa de ser um mero consumidor para se tornar um colaborador atuante. Nesse sentido, traz-se à colação:

A colaboração e a re-mixagem são práticas presentes nesta Web e contribuem para o exponencial crescimento de produtores de informação, pois uma parcela importante da humanidade deixa de ser mero consumidor de bens simbólicos e passa a integrar-se em uma sociedade que vê na colaboração e no remix uma nova forma de criação, uso e disseminação de conteúdo informacional. No contexto desse ambiente, também denominado Web Colaborativa, colaboração refere-se ao que Juliano Spyer em seu livro Conectado define como sendo um processo dinâmico cujo objetivo consiste em chegar a um resultado novo partindo das competências particulares dos grupos ou indivíduos envolvidos: “[...] na colaboração, existe uma relação de interdependência entre indivíduo e grupo, entre metas pessoais e coletivas, o ganho de um ao mesmo tempo depende e influência o resultado do conjunto." 35

A comunicação realizada via computadores pela internet tornou possível o acesso, a distribuição e a produção de conteúdos ao alcance de todos os usuários da rede, e a princípio, sem a necessidade de qualquer autorização ou concessão deste ou daquele governo, como se exige das emissoras de televisão, por exemplo. Como bem definido por Allan Rocha de Souza e Luca Schirru,

A evaporação do suporte físico como instrumento primordial de comunicação e controle da circulação da obra protegida por direitos autorais, e sua progressiva substituição pelo intangível, subverteu as estruturas de sustentação das indústrias culturais tradicionais (DANTAS, 2012), assim como viabilizou novas formas de expressão, criação e acesso. ${ }^{36}$

34 BEZERRA, Arthur Coelho. Direitos autorais e cultura da cópia na era digital. LOGOS 39: ética e autoria, v. 20, n. 2, p. 6-18, 2013. p. 7.

35 ARAYA, Elizabeth Roxana Mass; VIDOTTI, Silvana Aparecida Borsetti Gregorio. Direito autoral e tecnologias de informação e comunicação no contexto da produção, uso e disseminação de informação: um olhar para as licenças Crative Commons. Revista Informação \& Sociedade: Estudos, João Pessoa, v. 19, n. 3, p. 39-51, set./dez. 2009. p. 40.

36 SOUZA, Allan Rocha de; SCHIRRU, Luca. Os direitos autorais no Marco Civil da Internet. Liinc em Revista, Rio de Janeiro, v. 12, n. 1, p. 40-56, maio 2016. p. 41. 
Na verdade, com as novas tecnologias, surgiu a 'cibercultura, cujo princípio basilar são os novos modelos de criação, distribuição e coordenação, e tudo isso, em tempo real. É a cultura da participação, da manifestação coletiva na geração de conteúdos e na abertura de acesso ao que foi produzido, gerando, necessariamente, cópias desse material.

Os novos modelos baseados em padrões emergentes de informação e produção cultural compartilhada constituem um princípio básico da cibercultura apontado por Pierre Lévy (1999), a saber, a criação de uma inteligência coletiva, distribuída por toda parte e coordenada em tempo real, que resulta da mobilização das competências dos usuários da internet e que ganha com a soma dos conhecimentos. A inteligência coletiva pode ser percebida em projetos de criação abertos à participação dos usuários, como a Wikipédia e as comunidades de programadores de software livre. Esses e muitos outros exemplos representam aquilo que Clay Shirky define como a "cultura da participação", constituída por um "excedente cognitivo" recém-gerado a partir de ilhas de tempo e talento anteriormente desconectadas. Tal excedente agora se projeta graças à invenção e a disseminação de uma forma de mídia pública, que permite aos cidadãos comuns o uso de seu tempo livre (que até então era invariavelmente gasto em frente à TV) na busca de atividades das quais gostem ou com as quais se importem (SHIRKY, 2011, p. 30-31).

A cultura da participação descrita por Shirky, que pode ser entendida como expressão da inteligência coletiva aludida por Lévy, encontra-se cimentada em uma cultura da cópia digital de conteúdos, uma manifestação inalienável da cultura que se expressa na rede de computadores - que, afinal, foi projetada para que qualquer acesso a conteúdo gere, necessariamente, uma cópia desse conteúdo (LESSIG, 2004, p. 127). Assim é que o fluxo de bens culturais na internet compõe-se de uma tempestade de cópias que são ininterruptamente produzidas e compartilhadas pelos internautas. ${ }^{37}$

Como é de se notar, o rol de direitos autorais indicados no item anterior, cuja premissa basilar repousa na prerrogativa garantida de poder autorizar ou impedir, isto é, um poder de interditar a utilização ou divulgação indevida da obra nos meios intangíveis encontra seu maior entrave nesta nova cultura, originada nos novéis meios tecnológicos, cuja estrutura base é a internet (rede de computadores mundial) e as redes sociais (aplicativos e formas de agrupamento virtual).
BEZERRA, Arthur Coelho. Direitos autorais e cultura da cópia na era digital. LOGOS 39: ética e autoria, v. 20, n. 2 , p. 6-18, 2013. p. 7-8.
Mesmo que haja liberdade no tráfego informacional, uma certa falta de controle prévio, expansão irrestrita das fronteiras, o uso indiscriminado de textos e imagens e a nova economia digital, frente à modificação ou transformação, célere e abundante, na cultura, tornando mais complexa e problemática a proteção efetiva das criações autorais e conexas, o fato é que a violação a tais direitos encontram proteção Estatal nesse cenário.

\section{A proteção no cenário atual}

A considerar suas características imateriais, a propriedade intelectual vem sendo desafiada na rede mundial de computadores, provocando estudos preocupados com a sobrevivência do Copyright e do Droit d'Auteur. No campo virtual, vários aspectos atingem, diretamente, os conceitos básicos da proteção autoral, por exemplo: (a) a facilitação na produção e distribuição de cópias não autorizadas; (b) a execução pública de obras, sem autorização; (c) a manipulação não autorizada de originais digitalizados; e (d) a apropriação indevida de textos e imagens, ofertados via on line. ${ }^{38} \mathrm{O}$ sistema oriundo da internet é bem descrito nas seguintes palavras:

A melhor imagem para descrevê-la é a de uma infovia, uma estrada digital por onde trafegam riquezas devidamente transformadas em bits. Transformar átomos em bits significa digitalizar, reescrever a informação contida na voz, na cor, nas luzes, nas letras, nos filmes e nas formas, colocando tudo isso para viajar de uma tela para outra. O membro da Internet é o radioamador dos anos 1990, falando com o mundo todo de um escritório no fundo de casa, só que seu instrumento de comunicação está para o radiotransmissor assim como o Boeing está para a carroça [...] Os bits são a maior riqueza deste fim de século ou a sua mais completa tradução. As possibilidades de se exibir são infinitas. De repente, qualquer um pode ser um best seller mundial. Uma página de texto colocada por qualquer membro da Internet pode ser lida por milhões de pessoas. ${ }^{39}$

Para José Carlos da Costa Netto, a utilização de obras intelectuais na rede estão englobadas em três campos basicamente. $\mathrm{O}$ da reprodução (cf. art. $5^{\circ}$, n. VI, Lei 9619/98) consistente em "qualquer armazenamento permanente ou temporário por meios eletrônicos" (down-

38 GANDELMAN, Henrique. De Gutenberg à internet: direitos autorais na era digital. Rio de Janeiro: Record, 1997. p. 158.

39 CHAVES, Antonio. Direitos autorais na computação de dados. São Paulo: LTR, 1996. p. 240. 
load) ${ }^{40}$. O da distribuição (cf. art. $5^{\circ}$, n. IV c.c. art. 29 , n. VII, ambos da Lei 9619/98), referindo-se a primeira à "venda, locação ou qualquer outra forma de transferência ou posse" e a segunda à "seleção de obra ou produção" para colhê-la "em um tempo ou lugar previamente determinados por quem formula a demanda", e "nos casos em que o acesso às obras ou produções se faça por qualquer sistema que importe em pagamento pelo usuário"41. E, por fim, o da comunicação (cf. art. $5^{\circ}$, n. V, Lei 9.619/98), atinente ao ato de colocar a obra ao alcance do público, desde que não signifique a distribuição exemplares (exceção).

Com esse quadro, pondera o mesmo autor que o controle dos direitos autorais frente a essas modalidades envolve três possibilidades de proteção, a saber: i. do controle direto (feito diretamente pelo titular); ii. do controle indireto (exercido pelos titulares derivados (cessionários, representantes e administradores); e iii. do controle coletivo (exercido por entidade de gestão coletiva, representante dos titulares de certo gênero de obras e bens) $)^{42}$. Seguindo o raciocínio, aponta o autor para três regimes de controle: (a) regime originário de controle, exercível pelo titular sem qualquer documento de aquisição; (b) o regime condicionado à comprovação documental, em que o cessionário (titular derivado) ou representante (licenciado) dos direitos deverão comprovar a legitimidade; e (c) o regime legal de gestão coletiva, em que o exercício do direito e a proteção de certa modalidade de uso é regulado em lei para ser realizado de forma unificada (regime de substituição legal que independe de comprovação). ${ }^{43}$

Muito embora a internet tenha ganhado regulação no Brasil em 23 de abril de 2014, com a Lei $\mathrm{n}^{\circ} 12.965$ (Marco Civil da Internet), estabelecendo princípios, garantias, direitos e deveres para o uso da internet, não sobrevieram modificações quanto aos direitos autorais e conexos (por violações de direitos autorais na rede), estes só vieram a relegar o tratamento à própria Lei de Direitos Autorais (LDA). Por oportuno, tem-se o seguinte:

O que se verificou durante a tramitação do PLC $n^{\circ} 21 / 2014$ no Senado Federal foi que não ocorreu qualquer alteração substancial no tratamen-

$40 \quad$ COSTA NETTO, José Carlos. Estudos e pareceres de direito autoral. Rio de Janeiro: Forense, 2015. p. 298.

41 COSTA NETTO, José Carlos. Estudos e pareceres de direito autoral. Rio de Janeiro: Forense, 2015. p. 299.

42 COSTA NETTO, José Carlos. Estudos e pareceres de direito autoral. Rio de Janeiro: Forense, 2015. p. 299-300.

43 COSTA NETTO, José Carlos. Estudos e pareceres de direito autoral. Rio de Janeiro: Forense, 2015. p. 300. to aos direitos autorais através de propostas de emendas nessa Casa, prevalecendo, o acordo político alcançado pela Câmara. Dessa maneira, o resultado final do processo político-legislativo foi o afastamento definitivo de qualquer regulamentação sobre os direitos autorais no ambiente digital do escopo do Marco Civil da Internet, sua remissão à LDA em vigor, até que seja revista neste aspecto. ${ }^{44}$

Na verdade, não houve consenso mínimo nos debates para regulação dos direitos autorais no ambiente digital, remanescendo o reconhecimento da necessidade de uma regulação específica sobre o assunto para fins de compatibilizar a proteção da exclusividade e a liberdade de expressão (direitos fundamentais de igual envergadura $)^{45}$. Nessa linha, os dois textos que tratam de direitos autorais no Marco Civil estão assim grafados:

Art. 19. Com o intuito de assegurar a liberdade de expressão e impedir a censura, o provedor de aplicações de internet somente poderá ser responsabilizado civilmente por danos decorrentes de conteúdo gerado por terceiros se, após ordem judicial específica, não tomar as providências para, no âmbito e nos limites técnicos do seu serviço e dentro do prazo assinalado, tornar indisponível o conteúdo apontado como infringente, ressalvadas as disposições legais em contrário. [...]\$ 20 A aplicação do disposto neste artigo para infrações a direitos de autor ou a direitos conexos depende de previsão legal específica, que deverá respeitar a liberdade de expressão e demais garantias previstas no art. 5은 da Constituição Federal ${ }^{46}$.

Art. 31. Até a entrada em vigor da lei específica prevista no $₫ 2^{\circ}$ do art. 19, a responsabilidade do provedor de aplicações de internet por danos decorrentes de conteúdo gerado por terceiros, quando se tratar de infração a direitos de autor ou a direitos conexos, continuará a ser disciplinada pela legislação autoral vigente aplicável na data da entrada em vigor desta Lei. ${ }^{47}$

Calha assinalar, ainda, que, embora o Marco Civil

${ }_{44}$ SOUZA, Allan Rocha de; SCHIRRU, Luca. Os direitos autorais no Marco Civil da Internet. Liinc em Revista, Rio de Janeiro, v. 12, n. 1, p. 40-56, maio 2016. p. 52.

45 SOUZA, Allan Rocha de; SCHIRRU, Luca. Os direitos autorais no Marco Civil da Internet. Liinc em Revista, Rio de Janeiro, v. 12, n. 1, p. 40-56, maio 2016. p. 53.

46 BRASIL. Lei Federal n. 12.965 de 23 de abril de 2014. Altera, Estabelece princípios, garantias, direitos e deveres para o uso da Internet no Brasil. Disponível em: <http://www. planalto.gov.br/ccivil_03/_ato2011-2014/2014/lei/112965. htm>. Acesso em: 03 jul. 2016.

47 BRASIL. Lei Federal n. 12.965 de 23 de abril de 2014. Altera, Estabelece princípios, garantias, direitos e deveres para o uso da Internet no Brasil. Disponível em: <http://www. planalto.gov.br/ccivil_03/_ato2011-2014/2014/lei/112965. htm>. Acesso em: 03 jul. 2016. 
não tenha avançado no campo da responsabilidade dos provedores, para fins de proteção aos direitos autorais e conexos na rede (cf. art. $19, \$ 2^{\circ}$ combinado com o art. 31), é possível ao seu titular que se utilize do artigo 15 e seguintes da Lei, que cuida da guarda e do registro do conteúdo para fins de identificação do eventual violador.

Por sua vez, a Lei de Direitos Autorais permite ao titular exercer seus direitos, previstos no artigo $28^{\circ}$, violados em qualquer plataforma digital, notadamente, porque o próprio artigo $7^{\circ}$, ao abordar a questão da obra protegida, deixa bem claro que são aquelas “expressas por qualquer meio ou fixadas em qualquer suporte, tangível ou intangível, conhecido ou que se invente no futuro".

Desse modo, vulnerações aos direitos autorais e conexos ocorridas na internet (obras utilizadas sem autorização prévia e expressa - art. 29 da Lei) permitirão não só o ressarcimento pelos danos patrimoniais e morais, a identificação do infrator, como também, a prerrogativa do artigo 105 da indigitada Lei, assim transcrito:

\begin{abstract}
A transmissão e a retransmissão, por qualquer meio ou processo, e a comunicação ao público de obras artísticas, literárias e científicas, de interpretações e de fonogramas, realizadas mediante violação aos direitos de seus titulares, deverão ser imediatamente suspensas ou interrompidas pela autoridade judicial competente, sem prejuízo da multa diária pelo descumprimento e das demais indenizações cabíveis, independentemente das sanções penais aplicáveis; caso se comprove que o infrator é reincidente na violação aos direitos dos titulares de direitos de autor e conexos, o valor da multa poderá ser aumentado até o dobro. ${ }^{48}$
\end{abstract}

Em suma, ainda que inegável os obstáculos que as novas tecnologias trouxeram ao efetivo controle das obras intelectuais, a proteção legal, entretanto, remanesce sólida, e, para eficiência em sua aplicação exigirá do aplicador da ciência jurídica um olhar menos dogmático e mais zetético, fazendo a exata distinção em cada caso concreto para que se equilibrem, de um lado, os direitos autorais, e, de outro, o direito de acesso à informação.

\section{Conclusão}

Os direitos autorais e conexos possuem uma função social, a qual pode ser encontrada no artigo 215 da Consti-

$48 \quad$ BRASIL. Lei Federal n. 9610/1998. Altera, atualiza e consolida a legislação sobre os direitos autorais e dá outras providências. Brasília. 2016. Disponível em: <http://www. planalto.gov.br/ccivil_03/leis/L9610.htm>. Acesso em: 03 jul. 2016. tuição Federal de 1988, que, no capítulo referente à educação, cultura e desporto, estabelece: “o Estado garantirá a todos o pleno exercício dos direitos culturais e acesso às fontes da cultura nacional, e apoiará e incentivará a valorização e a difusão das manifestações culturais". Dessa regra, funda-se o entendimento de que é papel do Estado, enquanto ente dotado de personalidade jurídica, prover a estruturação da sociedade e o bem comum dos sujeitos nela inseridos, vindo daí a função social atribuída aos direitos autorais ${ }^{49}$.

As novas tecnologias da sociedade da informação, ainda que fomentadoras de uma nova cultura no fluxo e modo que o conhecimento ou os dados são transmitidos, reconhecidamente de difícil controle, não alteraram a questão da responsabilização na proteção aos direitos autorais e conexos (art. 105, Lei 9610/98), prevendo a legislação brasileira outros mecanismos eficientes para a proteção prevista, como por exemplo a obrigatoriedade de os provedores armazenarem e fornecerem o conteúdo e a provável identificação do suposto violador dos direitos autorais o conexos (cf. art. 15, Marco Civil da Internet), sem se descurar de outros princípios basilares do nosso ordenamento quanto à reparação de danos patrimoniais e extrapatrimoniais que ordena a "não lesão" a outrem, segundo o teor do art. 186 e art. 187 do Código Civil, desempenhando um poderoso papel nesta seara, podendo ser invocado nas situações em que a legislação ou prática não contiver uma especificação tal que fique clara a proteção (enfoque zetético do direito).

Ponto finalizando, pode-se dizer que os direitos autorais e conexos guardadas suas peculiaridades possuem função social e protegidos pela Constituiçãa ${ }^{50}$, legislação interna e internacional, estando submetidos seus preceitos protetivos mesmo na forma digital ou virtual, principalmente com o enfoque zetético, que caracteriza o direito na sociedade da informação.

\section{Referências}

ACESSO à internet chega a 49,4\% da população brasileira. Brasília: EBC, 2015. Disponível em: <http://www. ebc.com.br/tecnologia/2015/04/acesso-internet-chega-494-da-populacao-brasileira>. Acesso em: 02 nov. 2015.

49 BEZERRA, Arthur Coelho. Direitos autorais e cultura da cópia na era digital. LOGOS 39: ética e autoria, v. 20, n. 2, p. 6-18, 2013. p. 13.

50 BRASIL. Constituição (1988). Constituição da República Federativa do Brasil. Disponível em: <http://www.planalto.gov.br/ccivil_03/constituicao/constituicaocompilado. htm>. Acesso em: 03 jul. 2016. Art. 5º, incisos XXVIII e XXIX. 
ARAYA, Elizabeth Roxana Mass; VIDOTTI, Silvana Aparecida Borsetti Gregorio. Direito autoral e tecnologias de informação e comunicação no contexto da produçao, uso e disseminação de informação: um olhar para as licenças Crative Commons. Revista Informação \& Sociedade: Estudos, João Pessoa, v. 19, n. 3, p. 39-51, set./dez. 2009.

ASSIS, Olney Queiroz; KUMPEL, Vitor Frederico. Manual de antropologia jurídica. São Paulo: Saraiva, 2015.

BARBOSA, Marco Antonio. Pluralismo jurídico na sociedade da informação. Direitos Fundamentais \& Justiça, Porto Alegre, ano 6, n. 20, p. 114-134, jul./set. 2012.

BARBOSA, Marco Antonio; SANTOS, Marco Aurelio Moura dos. O direito na sociedade da informação e perspectivas para a sociedade do conhecimento. Direitos Fundamentais \& Justiça, Porto Alegre, ano 8, n. 28, p. 82-99, jul./set. 2014.

BEZERRA, Arthur Coelho. Direitos autorais e cultura da cópia na era digital. LOGOS 39: ética e autoria, v. 20, n. 2, p. 6-18, 2013.

BITTAR, Carlos Alberto. Direito de autor. 6. ed. Rio de Janeiro: Forense, 2015.

BRASIL. Constituição (1988). Constituição da República Federativa do Brasil. Disponível em: <http://www.planalto.gov.br/ccivil_03/constituicao/constituicaocompilado. htm>. Acesso em: 03 jul. 2016.

BRASIL. Lei Federal n. 9610, de 19 de fevereiro de 1998. Altera, atualiza e consolida a legislação sobre os direitos autorais e dá outras providências. Disponível em: <http:// www.planalto.gov.br/ccivil_03/leis/L9610.htm>. Acesso em: 03 jul. 2016.

BRASIL. Lei Federal n. 12.965 de 23 de abril de 2014. Altera, Estabelece princípios, garantias, direitos e deveres para o uso da Internet no Brasil. Disponível em: <http:// www.planalto.gov.br/ccivil_03/_ato2011-2014/2014/lei/ 112965.htm>. Acesso em: 03 jul. 2016.

BRAUN, Michele; ADOLFO, Luiz Gonzaga Silva. A gestão coletiva dos direitos autorais no Brasil: uma reflexão sobre o contexto tecnológico contemporâneo e a Lei 9610/98. Direito, Estado e Sociedade, Rio de Janeiro, n. 42, p. 194-212, jan./jun. 2013.
CASTELLS, Manuel. A galáxia da internet: reflexões sobre a internet, os negócios e a sociedade. Rio de Janeiro: J. Zahar, 2003.

CHAVES, Antonio. Direitos autorais na computação de dados. São Paulo: LTR, 1996.

COSTA NETTO, José Carlos. Estudos e pareceres de direito autoral. Rio de Janeiro: Forense, 2015.

FERRAZ JUNIOR, Tércio Sampaio. Introdução ao estudo do direito: técnica, decisão, dominação. 8. ed. São Paulo: Atlas, 2015.

FRAGOSO, João Henrique da Rocha. Direito autoral: da antiguidade à internet. São Paulo: Quartier Latin do Brasil, 2009.

GANDELMAN, Henrique. De Gutenberg à Internet: direitos autorais na era digital. Rio de Janeiro: Record, 1997.

GOMES, Helton Simões. Conexão à internet via smartphone dobra no Brasil diz Google. Disponível em: <http:// g1.globo.com/tecnologia/noticia/2015/08/conexao-internet-smartphone-dobra-no-brasil-em-2015-diz-google.html>. Acesso em: 15 jun. 2016.

IAMUNDO, Eduardo. Sociologia e antropologia do direito. São Paulo: Saraiva, 2013.

NINNI, Karina. O direito autoral na era da informação. Disponível em: <http://bibliotecadigital.fgv.br/ojs/index. php/pagina22/article/viewFile/28718/27577>. Acesso em: 30 jun. 2016.

PAESANI, Liliana Minardi. Direito e internet: liberdade de informação, privacidade e responsabilidade civil. 6. ed. São Paulo: Atlas, 2013.

SILVEIRA, Newton. Propriedade intelectual. 5. ed. São Paulo: Manole, 2014.

SOUSA, Rosilene Paiva Marinho de et al. O exercício da arquitetura da informação na web: reflexões relativas à lei dos direitos autorais. Revista eletrônica de biblioteconomia e ciência da informação, Santa Catarina, v. 18, n. 36, p. 107-128, jan./abr. 2013.

SOUZA, Allan Rocha de; SCHIRRU, Luca. Os direitos autorais no Marco Civil da Internet. Liinc em Revista, Rio de Janeiro, v. 12, n. 1, p. 40-56, maio 2016. 